\title{
Soil and weed management for enhancing arbuscular mycorrhiza colonization of wheat
}

\author{
I. Brito ${ }^{1}$, M. Carvalho ${ }^{1} \&$ M. J. Goss ${ }^{2}$ \\ ${ }^{1}$ Universidade de Évora - ICAAM, Apartado 94, 7002-554 Évora, Portugal, and ${ }^{2}$ University of Guelph, Kemptville Campus, \\ Kemptville, ON KOG 1J0, Canada
}

\begin{abstract}
Tillage and weed control are critical components of cropping systems that need to be combined such that crops benefit from reduced competition. However, weeds may also contribute to the biological diversity within the agro-environment. This greenhouse study investigated whether common weeds of arable cropping systems were suitable host plants for arbuscular mycorrhizal fungi (AMF), allowing the development of extraradical mycelium (ERM) that can contribute to the early colonization of a following wheat crop, especially in the absence of soil disturbance. Weeds were allowed to grow for up to 2 months before being controlled by soil disturbance or herbicide application (glyphosate or paraquat). Pregerminated wheat seeds were then planted. Chemical control of the weeds prior to sowing enhanced the early arbuscular mycorrhiza (AM) colonization rate of wheat roots, whereas mechanical disturbance was less acceptable as a method of weed control for rapid AM colonization. The type of herbicide (contact or systemic) had no impact on colonization of the wheat crop. Enhanced AM colonization promoted early $\mathrm{P}$ acquisition and growth of the crop. Appropriate management of weeds emerging between two consecutive cropping seasons coupled with no-till soil management could ensure a quick and efficient AM colonization of the following wheat plants.
\end{abstract}

Keywords: Arbuscular mycorrhiza fungi, herbicides, weed control method, weeds, wheat, soil disturbance

\section{Introduction}

Mechanical or chemical control of weeds in agricultural crops aims at eliminating competition for nutrients, water and light (Zimdahl, 2004). However, beneficial effects of weeds have been identified in certain cropping systems. For example, Feldmann \& Boyle (1999) report that the absence of weeds in continuous maize production was deleterious as it resulted in the reduction in the types of mycorrhizal spores present and the population of arbuscular mycorrhizal fungi (AMF) were less effective in supplying nutrients to the host crop. Nevertheless, many benefits accrue to plants from their association with AMF (Gupta et al., 2000). The ones most often described are related to acquisition of nutrients, particularly those that are less mobile, such as $\mathrm{P}$ (Covacevich et al., 2006). However, AMF can also act as parasite, even in situations where $\mathrm{P}$ availability is limited (Ryan et al., 2005).

Correspondence: I. Brito. E-mail: ibrito@uevora.pt Received August 2012; accepted after revision June 2013
Under Mediterranean conditions, it is common for weeds to germinate between two cropping seasons after autumn rain. AMF can colonize roots of most agricultural crops and weeds indiscriminately (Yamato, 2004), and their extraradical mycelium (ERM) can link different colonized plants (Newman et al., 1994). Moreover, in the autumn, weeds germinate when soil temperature is warmer, which is beneficial for AM colonization (Daniels \& Trappe, 1980). Kabir \& Koid (2000) showed the advantages of having mycotrophic cover crops to enhance the AM inoculum potential in agriculture systems. Consequently, with appropriate management, the weed population could play a role similar to cover crops in improving AM inoculum potential as well as enhancing the diversity of AMF under agricultural systems.

Soil hyphae are a more effective source of AM inoculum than spores under undisturbed soil conditions (Kabir, 2005). Knowing that ERM initiates AM colonization earlier and develops faster than do other types of propagule (Fairchild \& Miller, 1988; Martins \& Read, 1997), the benefits to nutrient acquisition, especially accumulation of $\mathrm{P}$, following AM colonization starting from ERM are well documented (Fairchild \& Miller, 1988; Goss \& de Varennes, 2002). 
Under no-till cropping systems, the ERM of the weeds is kept intact, creating a unique opportunity to enhance early colonization of the next crop. In addition, there are also possibilities for improved nutrient resource transfer between senescing weeds and the crop (Van Kessel et al., 1985; Johansen \& Jensen, 1996; Yao et al., 2003). Realizing the full potential of these opportunities requires knowledge of whether different methods of controlling weeds can influence the ability of the ERM associated with its roots to enhance early AM colonization of the next crop.

Under no-till, a preseeding herbicides, usually glyphosate [N-(phosphonomethyl) glycine] or paraquat [1,1'-dimethyl4.4'-bipyridilium ion], are applied to control the weeds. The effect of herbicides, including glyphosate and paraquat, on the AMF population and its ability to colonize the plant roots is not clear, and some results appear to be contradictory. For example, glyphosate applied to the foliage of weeds or to tolerant crops at recommended field rates had no negative effects on AM colonization (Powell et al., 2009; Reis et al.,2010). Pope \& Holt (1980) found similar results for paraquat and Ryan et al. (1994) found no effect of diclofopmethyl and diflufenican and bromoxynil. However, Abd-Alla et al. (2000) found that, if mixed into the soil, paraquat and bromoxynil reduced AM colonization of grain legumes. Pope \& Holt (1980) also reported that applying glyphosate at double the recommended rate impaired AM colonization. However, Sheng et al. (2012) found that although glyphosate had no effect on the rate of AMF colonization, it modified the composition of AM community, which could interfere in the final outcome of the symbiosis as there is a degree of functional diversity within AMF (Garg \& Chandel, 2010).

The objectives of this investigation were therefore to evaluate whether the integrity of the ERM from indigenous AMF, associated with the roots of common weeds of cereal cropping systems, as influenced by the method of weed control, can influence mycorrhizal colonization of a following wheat crop.

Wheat was selected as the recipient host used in this study because of its importance worldwide, even though there is a wide range in the AMF colonization rate and effectiveness reported for this crop. For example, wheat varieties differ greatly in the degree by which they are colonized by AMF (Azcón \& Ocampo, 1981) and the ability of the symbiosis to improve biomass and yields ranges from negative (a parasitic effect) (Ryan et al., 2005) to five times greater yields than for nonmycorrhizal plants (Karagiannidis \& HadjisavvaZinoviadi, 1998).

\section{Materials and methods}

The main objective of this study was to investigate whether AM colonization starting from an intact extraradical mycelium (ERM) developed from indigenous
AMF population on common weeds would enhance the AMF colonization rate of wheat, resulting in a more rapid initial growth and $\mathrm{P}$ uptake. Wheat (Triticum aestivum L., var. Coa) was chosen as the test crop, being an important modern high yielding variety for the region. The most common grass weeds in the southern regions of Portugal, Persian ryegrass (Lolium rigidum Gaudin), wild oat (Avena sterilis L.) and little seed canary grass (Phalaris minor Retz.) were used in the study. A greenhouse pot experiment was developed with two stages. In the first stage, the selected weeds were grown to develop the AMF extraradical mycelium (ERM). To create two contrasting states of ERM integrity, the weeds were then controlled with or without soil disturbance, that is, the ERM was either disrupted or kept intact. In the second stage of the experiment, wheat was planted in each pot and grown for two different lengths of time. The experiment therefore considered two factors: the integrity of the ERM at the beginning of stage two (factor 1) and the duration of the period of wheat growth (factor 2). Experiment 1 was repeated to validate the working hypothesis but with some simplifications and adjustments to obtain supplementary information (Experiment 2).

\section{Experiment 1}

There were three treatments with five replicates: soil disturbance (ERM disrupted) and two types of herbicide, paraquat and glyphosate (ERM kept intact). The two herbicides were chosen, as they have contrasting modes of action (paraquat - contact, glyphosate - systemic), and systemic fungicides have been shown to be more effective on AMF than contact types (Menge, 1982). Consequently, it was possible to investigate if they exerted different influences on the infectivity of the ERM and the performance of the AM symbiosis.

One pregerminated seed of each of the selected weed species was planted in each of thirty 6L-plastic pots containing $6 \mathrm{~kg}$ soil. After 2 months of growth, weeds were controlled by the appropriate method. For chemical control, weeds were sprayed with a volume equivalent to $300 \mathrm{~L} / \mathrm{ha}$ containing $2 \mathrm{~g} / \mathrm{L}$ paraquat $\left(\right.$ Gramoxone $^{\circledR}$ ) or $3.6 \mathrm{~g} / \mathrm{L}$ glyphosate (Roundup ${ }^{\circledR}$ ).

For mechanical control, shoots were first excised, and then the soil was removed from each pot as two layers of ca. $0.2 \mathrm{~m}$ depth and passed separately through a $4 \mathrm{~mm}$ sieve. All root material separated on the sieve was cut into 2-cm-long segments and mixed into the soil of the appropriate layer. Soil was repacked in the pots and arranged in the same two layers. Shoot material was cut into small fragments and mixed into the top layer.

Pots were left for 12 days to allow the herbicides to act. For the second stage of the experiment, 4 pregerminated wheat seeds (5 days old) were placed in each pot and allowed to grow for 14 or 21 days. 
The parameters measured were the AM colonization rate of roots, shoot dry weight and $\mathrm{P}$ acquisition by the wheat for both growth periods.

To determine AM colonization rate, roots were carefully removed, washed and stained with $0.1 \%$ Trypan Blue in lactoglycerol (Phillips \& Hayman, 1970). AM colonization assessment was carried out according to the magnified intersections method (McGonigle et al., 1990), which gives colonization as nondimensional parameter expressed as a fraction. Shoots were dried at $70{ }^{\circ} \mathrm{C}$ for $48 \mathrm{~h}$ and then weighed. A composite plant sample of the five replicas of each treatment was ground and analysed for $\mathrm{P}$ content by colorimetry, after ashing the samples at $500{ }^{\circ} \mathrm{C}$ and dissolving the residue in $0.3 \mathrm{M} \mathrm{HCl}$.

The soil used was a Luvisol collected in the autumn from the top $20 \mathrm{~cm}$ of an arable field at Revilheira farm, Alentejo $\left(38^{\circ} 28^{\prime} \mathrm{N} 7^{\circ} 28^{\prime} \mathrm{W}\right)$. Basic fertility assessment showed that the air-dried and sieved (4 mm) soil contained $18 \mathrm{mg} \mathrm{P}_{2} \mathrm{O}_{5} / \mathrm{kg}$, $72 \mathrm{mg} \mathrm{K}{ }_{2} \mathrm{O} / \mathrm{kg}, 24 \mathrm{mg} \mathrm{NO}-\mathrm{N} / \mathrm{kg}, 13 \mathrm{mg} \mathrm{OM} / \mathrm{g}$ and had a $\mathrm{pH}$ (water) of 6.1. Soil was air-dried and sieved before use, but otherwise untreated. Pots were kept in a greenhouse and watered (to weight) every 2 days to approximately field capacity $(0.17 \mathrm{~g} / \mathrm{g})$. The minimum temperature in the greenhouse was set at $17^{\circ} \mathrm{C}$, and the maximum temperature was set at $30{ }^{\circ} \mathrm{C}$.

The ANOVA was performed considering a two factor experimental arrangement. Factor 1 with three levels (weeds controlled by soil disturbance, weeds controlled by glyphosate, weeds controlled by paraquat) and factor 2 with two levels according to the period of wheat growth (14 and 21 days).

\section{Experiment 2}

The experiment was simplified without changing the working hypothesis, but the number of pots in stage 1 was modified to allow determination of AMF colonization parameters for the weeds. The duration of weed growth was reduced to 1 month. Only glyphosate was used as the herbicide treatment, given that in Experiment 1, there was no significant effect on colonization of the type of herbicide. The period of wheat growth was increased to 21 and 28 days, because in Experiment 1 the significance of the difference between treatments of factor 1 , increased between 14 and 21 days of wheat growth. Because the time for which the wheat grew was longer, $\mathrm{N}, \mathrm{Zn}$ and $\mathrm{S}$ were applied in stage 2 of the experiment to ensure other nutrients would not limit plant response to $\mathrm{P}$.

One week after planting the wheat, $\mathrm{N}$ was applied as $\mathrm{NH}_{4} \mathrm{NO}_{3}$ at a rate of $50 \mathrm{mg} \mathrm{N} / \mathrm{kg}$ dry soil, equivalent to $120 \mathrm{~kg}$ of $\mathrm{N} / \mathrm{ha}$. At the same time, $\mathrm{Zn}$ was applied as $\mathrm{ZnSO}_{4}$ at a rate of $3.4 \mathrm{mg} \mathrm{Zn}$ and $1.7 \mathrm{mg} \mathrm{S} / \mathrm{kg}$ dry soil $(8 \mathrm{~kg}$ of $\mathrm{Zn}$ and $4 \mathrm{~kg}$ of $\mathrm{S} / \mathrm{ha})$.

The soil used in Experiment 1 was reused for this second experiment after the material from all the pots had been thoroughly mixed together, passed through a 4-mm sieve and then repotted, to eliminate any possible carryover effects of the treatments from Experiment 1. The total number of pots was 25 (20 for the two soil disturbance treatments, two periods of growth for the wheat, with fivefold replication, and five extra pots that were used at the end of stage 1 to investigate AM root colonization rate of the weeds).

An ANOVA was performed for a complete randomized block design with two factors, one with two levels consisting of the treatments under study (weeds controlled by soil disturbance and weeds controlled by glyphosate) and one, also with two levels, based on the period of wheat growth (21 and 28 days). All procedures for this experiment not specifically described above were the same as those used in Experiment 1.

For the common wheat growth period in the two experiments (21 days), an ANOVA was performed using a combined one factor model (weeds control method) with two levels (soil disturbance and glyphosate).

\section{Results}

\section{Experiment 1}

Mycorrhizal colonization of the wheat (arbuscular and hyphal) was affected by the weeds control method (Table 1). Soil disturbance to control weeds induced significantly smaller arbuscular (AC) and hyphal (HC) colonization after both growing periods. At 14 days after planting (DAP), the shoot dry matter of the wheat was greater after soil disturbance treatment, but by 21 DAP the glyphosate treatment resulted in a significant increase on the growth. Phosphorus uptake was not affected by treatment at 14 DAP, but by 21 DAP it was significantly greater in the herbicide treatments than in the disturbed soil (Table 1). As the shoots from the five replicas were all weighed together, no statistical information could be determined for the 14

Table 1 Effect of weed control method on growth and AM colonization parameters of wheat (Experiment 1)

\begin{tabular}{lcclc}
\hline & & \multicolumn{3}{c}{ Method of weed control } \\
\cline { 3 - 5 } $\begin{array}{l}\text { Measured } \\
\text { parameters }\end{array}$ & $\begin{array}{c}\text { Days after } \\
\text { planting }\end{array}$ & Glyphosate & Paraquat & Disturbance \\
\hline Shoot dry & 14 & $0.041 \mathrm{c}$ & n.d. & $0.065 \mathrm{~b}$ \\
$\quad$ matter (g/pot) & 21 & $0.097 \mathrm{a}$ & $0.081 \mathrm{ab}$ & $0.072 \mathrm{~b}$ \\
$\mathrm{P}$ uptake & 14 & $0.04 \mathrm{~d}$ & n.d. & $0.07 \mathrm{~cd}$ \\
$\quad$ (mg/pot) & 21 & $0.40 \mathrm{a}$ & $0.30 \mathrm{~b}$ & $0.12 \mathrm{c}$ \\
Hyphal & 14 & $0.68 \mathrm{~b}$ & $0.75 \mathrm{ab}$ & $0.48 \mathrm{c}$ \\
$\quad$ colonization & 21 & $0.84 \mathrm{a}$ & $0.77 \mathrm{ab}$ & $0.46 \mathrm{c}$ \\
Arbuscular & 14 & $0.35 \mathrm{a}$ & $0.36 \mathrm{a}$ & $0.08 \mathrm{~b}$ \\
$\quad$ colonization & 21 & $0.40 \mathrm{a}$ & $0.33 \mathrm{a}$ & $0.14 \mathrm{~b}$ \\
\hline
\end{tabular}

For each measured parameter, means followed by the same letter are not significantly different $(\alpha=0.05)$. n.d., not determined. 
DAP wheat plants from the paraquat treatment. However, the mean values for this treatment were $0.06 \mathrm{~g} /$ pot for shoot dry matter and $0.05 \mathrm{mg} \mathrm{P} /$ pot for $\mathrm{P}$ uptake. At $21 \mathrm{DAP}$, the AM colonization parameters and shoot dry matter of the wheat were not significantly different between the two herbicide treatments, but the acquisition of $\mathrm{P}$ was significantly less after paraquat than after glyphosate (Table 1).

At 21 DAP, there was no correlation between arbuscular colonization and shoot dry weight $(P=0.11)$ of the wheat (Figure 1a), but P uptake was proportional to the level of arbuscular colonization (Figure 1b).

\section{Experiment 2}

The average hyphal and arbuscular colonization of little seed canary grass, wild oat and Persian ryegrass roots 1 month after planting were $0.16( \pm 0.023)$ and $0.11( \pm 0.008)$, respectively. This was relatively small in comparison with the values found for wheat (Table 2).

Shoot dry matter of wheat was not significantly affected by treatment. However, AM colonization parameters (AC and $\mathrm{HC}$ ) and $\mathrm{P}$ uptake were significantly reduced by soil disturbance for both periods of wheat growth (Table 2).

There was a positive and highly significant correlation between arbuscular colonization and wheat plant growth (Figure 2a) and $\mathrm{P}$ uptake (Figure 2b) at 21 days after wheat planting $(P<0.01)$.

Analysis of the combined data from the two experiments for the common period of wheat growth (21 DAP), weed control by soil disturbance significantly reduced all values of the parameters measured relative to those of the herbicide treatment (Table 3).

\section{Discussion}

Consistent with our initial hypothesis, the use of herbicides to control weeds increased the AM inoculation potential
Table 2 Effect of weed control method on plant growth and AM colonization parameters of wheat (Experiment 2)

\begin{tabular}{lclc}
\hline & & \multicolumn{2}{l}{ Method of weed control } \\
\cline { 3 - 4 } Measured parameters & $\begin{array}{c}\text { Days after } \\
\text { planting }\end{array}$ & Glyphosate & Disturbance \\
\hline Shoot dry matter (g/pot) & 21 & $1.22 \mathrm{~b}$ & $1.02 \mathrm{~b}$ \\
& 28 & $2.72 \mathrm{a}$ & $2.65 \mathrm{a}$ \\
P uptake (mg/pot) & 21 & $2.70 \mathrm{c}$ & $2.03 \mathrm{~d}$ \\
& 28 & $6.20 \mathrm{a}$ & $5.53 \mathrm{~b}$ \\
Hyphal colonization & 21 & $0.39 \mathrm{~b}$ & $0.22 \mathrm{c}$ \\
Arbuscular colonization & 28 & $0.48 \mathrm{a}$ & $0.29 \mathrm{c}$ \\
& 21 & $0.28 \mathrm{ab}$ & $0.18 \mathrm{c}$ \\
& 28 & $0.33 \mathrm{a}$ & $0.23 \mathrm{bc}$ \\
\hline
\end{tabular}

For each measured parameter, means followed by the same letter are not significantly different $(P \leq 0.05)$.

for the following wheat crop relative to mechanical control. Early colonization was associated with the presence of an intact ERM when the seeds were sown. Under these conditions, weeds were able to enhance the AM colonization parameters of the crop, which was consistent with the results of Feldmann \& Boyle (1999). However, in the experiment of Feldmann \& Boyle (1999), the weeds were present concurrently with the crop, when a degree of competition between the two would be inevitable. In our study, weeds never coexisted with the wheat, and there was no competition between the two. The common weeds of Mediterranean arable fields tested in this study were able to promote the development of an extraradical mycelium and, when it was kept intact, the initial AM colonization of the crop was enhanced. This was consistent with the conclusion that AMF colonized indiscriminately the roots of most agricultural crops and weeds (Yamato, 2004). Importantly, even though the level of AM arbuscular colonization of the weeds was only $0.11 \pm 0.008$, they promoted extraradical mycelium development and AM bridging to the wheat crop.
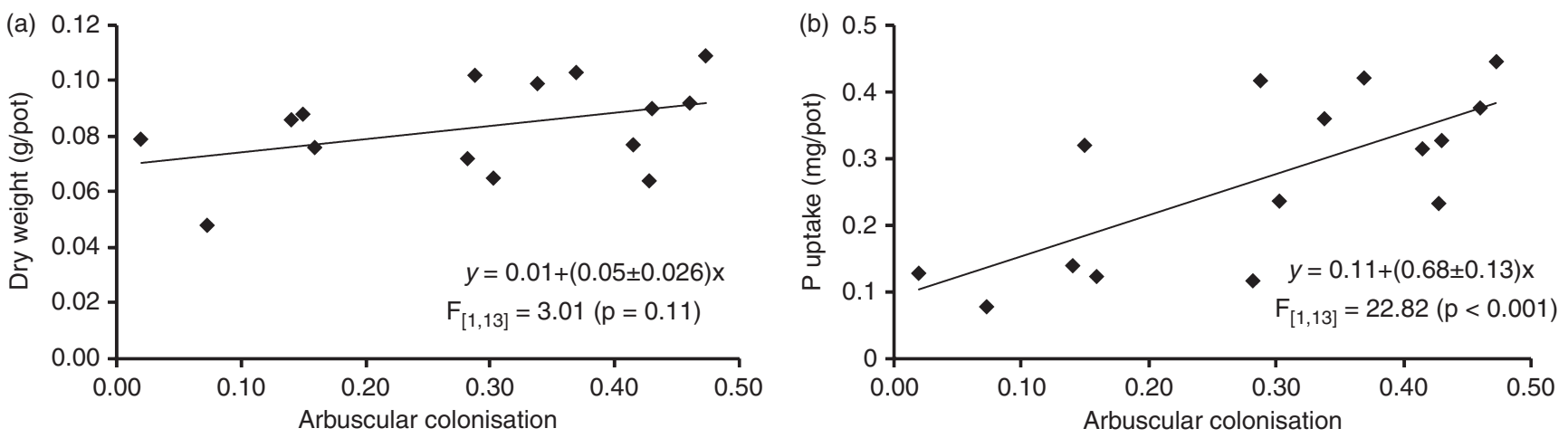

Figure 1 Correlation between arbuscular colonization and (a) shoot dry weight; (b) P uptake in wheat (Triticum aestivum, L.) 21 days after planting. Results from Experiment 1. 

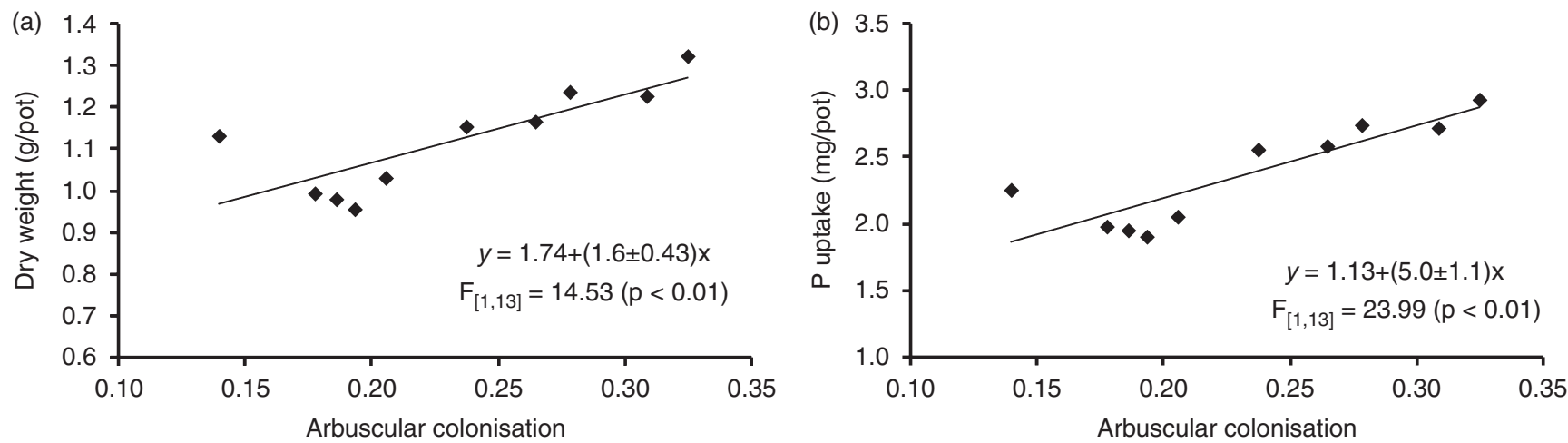

Figure 2 Correlation between arbuscular colonization and (a) shoot dry weight; (b) P uptake in wheat (Triticum aestivum, L.) 21 days after planting. Results from Experiment 2.

The method of weed control had a significant impact on the effectiveness of bridging between the weeds and the crop. Mechanical weed control significantly reduced the level of AM colonization of the wheat plants in both experiments relative to the use of herbicide, probably by disrupting the extraradical mycelium associated with the roots of the weeds. This hypothesis is consistent with the basic concepts proposed by Newman et al. (1994) that extraradical mycelium can link different plants, and if kept intact, ERM is a better source of propagule to start AM colonization (Fairchild \& Miller, 1988; Martins \& Read, 1997). Considering that weeds and the crop were not present at the same time, the benefit of having an enhanced AM colonization of the crop can only be obtained if the ERM is kept intact, as postulated and confirmed by the results of this study. Considering that the AM colonization rate of the wheat at $21 \mathrm{DAP}$, when the weeds were controlled by herbicide, was much larger than those observed for the weeds, results have significant practical implications for winter sown cereals under field conditions. It is especially relevant to limited-input cropping systems, where the mycorrhiza symbiosis is expected to increase its importance. Consequently, where mycorrhizas appear to be beneficial weeds should be eliminated by herbicide application and the crop seeded by no-till. Under conditions where the AMF are parasitic (e.g. Ryan et al., 2005), the use of no-till would be

Table 3 Effect of weed control method on plant growth, P uptake and AM colonization parameters at 21 days after planting. Mean values of the two experiments

\begin{tabular}{lcc}
\hline & \multicolumn{2}{c}{ Method of weed control } \\
\cline { 2 - 3 } Measured parameters & Glyphosate & Disturbance \\
\hline Shoot dry matter (g/pot) & $0.658 \mathrm{a}$ & $0.545 \mathrm{~b}$ \\
P uptake (mg/pot) & $1.549 \mathrm{a}$ & $1.072 \mathrm{~b}$ \\
Hyphal colonization & $0.612 \mathrm{a}$ & $0.340 \mathrm{~b}$ \\
Arbuscular colonization & $0.342 \mathrm{a}$ & $0.158 \mathrm{~b}$ \\
\hline
\end{tabular}

For each measured parameter, means followed by different letter are significantly different $(P \leq 0.05)$. expected to be more detrimental to the crop than intensive soil disturbance.

The difference in mode of action between the two herbicides tested in Experiment 1 had little effect on the wheat AM colonization parameters, indicating that herbicide was of little importance in the infectivity of the ERM, supporting the views of Reis et al. (2010), Powell et al. (2009) and Ryan et al. (1994) but not that of Abd-Alla et al. (2000).

At 21 DAP, the common timing for the evaluation of wheat growth in the two experiments, improvement in wheat growth (Figure 2a) and $\mathrm{P}$ uptake (Figures $1 \mathrm{~b}$ and $2 \mathrm{~b}$ ), was consistent with greater arbuscular colonization indicating that wheat derived a nutritional advantage from an enhanced AM colonization as found by Karagiannidis \& HadjisavvaZinoviadi (1998). In fact, the combined analysis of the two experiments showed that, not only AM colonization of wheat significantly improved $(P<0.05)$ but also the growth of the shoots and uptake of $\mathrm{P}$ were significantly increased $(P<0.05)$ (Table 3), when the ERM initiated on weed roots remained intact (weeds controlled by herbicide). Hetrick et al. (1993) found that current wheat cultivars are much less responsive to AMF compared with cultivars released before 1950. However, in spite of the fact that we used a modern wheat variety, the crop was able to benefit from AM colonization, indicating that this concept can be introduced in current cropping systems. Effective mycorrhizal colonization of autumn-sown wheat is difficult because of direct impacts of temperature on spore germination (Daniels \& Trappe, 1980; Kosk, 1981). We hypothesized that weeds could play an important role to overcome this limitation, assuming they germinate at the beginning of the new season, several weeks before the typical time to sow wheat, and being able to support the development of an ERM at this time. According to our results, if weeds are chemically controlled and the extraradical mycelium is kept intact (no-till seeding techniques), the AM colonization of the roots of young wheat plants can be enhanced by autumngerminating weeds because this faster colonizing form of inoculum (Read et al., 1976) is available, and apparently the period needed for the weeds to develop an appropriate 
extraradical mycelium fits within the normal agronomic calendars.

The weeds tested (Lolium rigidum Gaudin, Avena sterilis L. and Phalaris minor Retz.) acted as intermediate host plants able to develop an extraradical mycelium and promoted AM bridging to the following cereal crop. Mechanical disturbance was clearly a less appropriate method for weed control when benefits of AM colonization are desirable for optimum growth of the following crop.

There was no effect of the mode of action of the herbicide used to control weeds on AM colonization, as measured by either hyphal or arbuscular presence. However, the type of herbicide was found to be a critical factor in the level of benefit to be gained by wheat from the enhanced acquisition of $\mathrm{P}$ following colonization initiated by intact ERM. The greater AM colonization of wheat, when weeds were controlled by herbicides rather than by mechanical disturbance, promoted early $\mathrm{P}$ acquisition and growth of the crop, but the amount was $25 \%$ greater with the systemic glyphosate than the contact-acting paraquat. This suggests that the effectiveness of the AMF colonizing the roots following the different herbicides is altered, possibly by modifying the community structure (Sheng et al., 2012). The adoption of no-till and proper management of weed populations that emerge between two consecutive cropping seasons could provide a valuable tool to ensure a quick and efficient AM colonization of young wheat seedlings.

\section{References}

Abd-Alla, M.H., Omar, S.A. \& Karanxha, S. 2000. The impact of pesticides on arbuscular mycorrhizal and nitrogen-fixing symbioses in legumes. Applied Soil Ecology, 14, 191-200.

Azcón, R. \& Ocampo, J.A. 1981. Factors affecting the vesiculararbuscular infection and mycorrhizal dependency of thirteen wheat cultivars. New Phytologist, 87, 677-685.

Covacevich, F., Marino, M.A. \& Echeverría, H.E. 2006. The phosphorus source determines the arbuscular mycorrhizal potential and the native mycorrhizal colonization of tall fescue and wheatgrass. European Journal of Soil Biology, 42, 127-138.

Daniels, B.A. \& Trappe, P.M. 1980. Factors affecting germination of the VAM fungus Glomus epigaeus. Mycologia, 72, 457-471.

Fairchild, G.L. \& Miller, M.H. 1988. Vesicular-arbuscular mycorrhizas and the soil-disturbance-induced reduction of nutrient absorption in maize II Development of the effect. New Phytologist, 110, 75-84.

Feldmann, F. \& Boyle, C. 1999. Weed mediated stability of arbuscular mycorrhizal effectiveness in maize monocultures. Angewandte Botanik, 73, 1-5.

Garg, N. \& Chandel, S. 2010. Arbuscular mycorrhizal networks: process and functions A review. Agronomy for Sustainable Development, 30, 581-599.

Goss, M.J. \& de Varennes, A. 2002. Soil disturbance reduces the efficacy of mycorrhizal associations for early soybean growth and $\mathrm{N}_{2}$ fixation. Soil Biology \& Biochemistry, 34, 1167-1173.
Gupta, V., Satyanarayana, T. \& Garg, S. 2000. General aspects of mycorrhiza. In: Mycorrhizal biology (eds K.G. Mukerji, B.P. Chamola \& J.E. Singh), pp. 27-44. Kluwer Academic/Plenum, New York, NY.

Hetrick, B.A.D., Wilson, G.W.T. \& Cox, T.S. 1993. Mycorrhizal dependence of modern wheat cultivars and ancestors: a synthesis. Canadian Journal of Botany, 71, 512-518.

Johansen, A. \& Jensen, E.S. 1996. Transfer of N and P from intact or decomposing roots of pea to barley interconnected by an arbuscular mycorrhizal fungus. Soil Biology \& Biochemistry, 28, 73-81.

Kabir, Z. 2005. Tillage or no-tillage: Impact on mycorrhizae. Canadian Journal of Plant Science, 85, 23-29.

Kabir, Z. \& Koid, R.T. 2000. The effect of dandelion or cover crop on mycorrhiza inoculum potential, soil aggregation and yield of maize. Agriculture, Ecosystems \& Environment, 78, 167-174.

Karagiannidis, N. \& Hadjisavva-Zinoviadi, S. 1998. The mycorrhizal fungus Glomus mosseae enhances growth, yield and. chemical composition of a durum wheat variety in 10 different soils. Nutrient Cycling in Agroecosystems, 52, 1-7.

Koske, R.E. 1981. A preliminary study of interactions between species of vesicular-arbuscular mycorrhizal fungi in a sand dune. Transactions of the British Mycological Society, 76, 411-416.

Martins, M.A. \& Read, D.J. 1997. The effects of disturbance on the external mycelium of arbuscular mycorrhizal fungi on plant growth. Pesquisa Agropecuária Brasileira, 32, 1183-1189.

McGonigle, T.P., Miller, M.H., Evans, D.G., Fairchild, G.L. \& Swan, J. 1990. A new method which gives an objective measure of colonization of roots by vesicular-arbuscular mycorrhizal fungi. New Phytologist, 115, 495-501.

Menge, J.A. 1982. Effect of soil fumigants and fungicides on vesicular-arbuscular fungi. Phytopathology, 72, 1125-1132.

Newman, E.I., Devoy, C.L.N., Easen, N.J. \& Fowles, K.J. 1994. Plant species that can be linked by VA mycorrhizal fungi. New Phytologist, 126, 691-693.

Phillips, J.M. \& Hayman, D.S. 1970. Improved procedures for clearing roots and staining parasitic and vesicular-arbuscular mycorrhizal fungi for rapid assessment of infection. Transactions of the British Mycological Society, 55, 158-161.

Pope, P.E. \& Holt, H.A. 1980. Paraquat influences development and efficacy of the mycorrhizal fungus Glomus fasciculatus. Canadian Journal of Botany, 59, 518-521.

Powell, J.R., Campbell, R.G., Dunfield, K.E., Gulden, R.H., Hart, M.M., Levy-Booth, D.J., Klironomos, J.N., Pauls, K.P., Swanton, C.J., Trevors, J.T. \& Antunes, P.M. 2009. Effect of glyphosate on the tripartite symbiosis formed by Glomus intraradices, Bradyrhizobium japonicum, and genetically modified soybean. Applied Soil Ecology, 41, 128-136.

Read, D.J., Koveheri, H.K. \& Hodson, J. 1976. Vesicular-arbuscular mycorrhiza in natural vegetation systems. New Phytologist, 77, 641-653.

Reis, M.R., Silva, A.A., Pereira, J.L., Freitas, M.A.M., Costa, M.D., Silva, M.C.S. \& Santos, E.A. 2010. Impact of glyphosate associated with endosulphan and tebuconazole on the endosymbiotic microorganisms of the soybean. Planta Daninha, 28, 113-121.

Ryan, M.H., Chilvers, G.A. \& Dumaresq, D.C. 1994. Colonization of wheat by VA-mycorrhizal fungi was found to be higher on a farm managed in an organic manner than on a conventional neighbour. Plant and Soil, 160, 33-40. 
Ryan, M.H., Van Herwaarden, A.F., Angus, J.F. \& Kirkegaard, J.A. 2005. Reduced growth of autumn-sown wheat in a low P soil is associated with high colonization by arbuscular mycorrhizal fungi. Plant and Soil, 270, 275-286.

Sheng, M., Hamel, C. \& Fernandez, M.R. 2012. Cropping practices modulate the impact of glyphosate on arbuscular mycorrhizal fungi and rhizosphere bacteria in agroecosystems of the semiarid prairie. Canadian Journal of Microbiology, 58, 990-1001.

Van Kessel, C., Singleton, P.W. \& Hoben, H.J. 1985. Enhanced Ntransfer from a soybean to maize by vesicular arbuscular mycorrhizal (VAM) fungi. Plant Physiology, 79, 562-563.
Yamato, M. 2004. Morphological types of arbuscular mycorrhizal fungi in roots of weeds on vacant land. Mycorrhiza, 14, $127-131$.

Yao, Q., Li, X.L., Ai, W.D. \& Christie, P. 2003. Bi-directional. transfer of phosphorus between red clover and perennial ryegrass via arbuscular mycorrhizal hyphal links. European Journal of Soil Biology, 39, 47-54.

Zimdahl, R.L. 2004. Weed-crop competition: A review, 2nd edn. Blackwell Publishing Professional, Ames, IA. 